\title{
AUDIODESCRIÇÃO: PRIMEIROS PASSOS
}

\section{Larissa Costa e Maria Paula Frota}

\section{Introdução}

A partir de meados do século XX, com a popularização do cinema, do rádio e da $\mathrm{TV}$, a produção e o recebimento de informações foram substancialmente alterados e ampliados, se não inaugurando, consolidando a chamada "era das telecomunicações". Como mostra Denis Moraes na apresentação da coletânea Sociedade midiatizada, vivemos em meio a "redes, sistemas e circuitos [que] tecem um emaranhado de imagens, sons, efeitos especiais, palavras e discursos que subverte cronologias e lugares"; vivemos, ainda segundo o autor, em uma "sociedade saturada de impactos audiovisuais e acessos desiguais a tecnologias e conhecimentos" (2006: 10-11) — em poucas palavras, é na cultura do audiovisual que vivemos hoje.

Segundo o Dicionário Aurélio, "audiovisual” designa "a mensagem constituída de som e imagem", "os sistemas, meios ou veículos de comunicação que atingem o indivíduo receptor através dos canais auditivo e visual" (1996: 199). Os audiodescritores costumam usar o termo "audiovisual" de modo a abranger diferentes áreas como cinema, teatro, TV, videogames etc., sem restringi-lo, como muitos o fazem, à comunicação mediada por aparatos eletro-eletrônicos. A abrangência do termo continua e provavelmente continuará ampliando-se, de acordo com o surgimento de novas áreas e mídias de produção audiovisual, como já é o caso de mídias digitais para internet e celular.

O veículo de maior notoriedade na cultura do audiovisual é, sem dúvida, a televisão. Estima-se que $70 \%$ da população mundial tenham pelo menos um aparelho de TV em casa e esse número é bem maior no Brasil, cuja estimativa, segundo os dados da Pesquisa Nacional por Amostra de Domicílios (PNAD) de 2009, é de que 96\% dos domicílios têm aparelhos de TV. Outras mídias partícipes da cultura do audiovisual caminham a passos largos nessa mesma direção, produzindo discursos, regendo comportamentos, desejos de consumo etc. - ou seja, sendo estruturantes, constitutivas da sociedade contemporânea. A título de ilustração, vale mostrar outros resultados daquela mesma pesquisa nacional: 
Em 2001, 12,6\% dos domicílios [brasileiros] tinham microcomputador, alcançando $35,1 \%$ em 2009. No mesmo período, o crescimento do percentual de domicílios que possuíam microcomputador com acesso à Internet foi de 8,5\% para 27,7\% (site do IBGE).

É nesse cenário que precisamos nos conscientizar do seguinte: se por um lado as produções com imagem e som simultâneos são manifestações culturais intrínsecas à nossa vida em sociedade e nela tomam cada vez mais espaço, por outro lado há parcelas consideráveis da população — sobretudo as pessoas com deficiência visual ou auditiva - que estão total ou parcialmente excluídas desse mundo audiovisual. Aqueles que não têm acesso a um desses canais acabam ficando, de alguma forma, à parte do processo informacional, comunicacional e, em consequência, à margem do processo de socialização.

Felizmente, a partir da década de 1990 vem-se dando um avanço científico e tecnológico significativo para essas parcelas da população. Com a disseminação da internet e o surgimento de aparatos ligados à informática — como, por exemplo, os sintetizadores de voz, softwares de reconhecimento de fala, simuladores de mouses e teclados com controles sensíveis a ações voluntárias -, abriram-se novas perspectivas para a inclusão social (ver Mazzoni et alii, 2001). A audiodescrição (AD), a janela de LIBRAS e a legenda para surdos e ensurdecidos (LSE) constituíram-se nesse contexto, todas elas recursos de tecnologia assistiva voltados para a inclusão e a acessibilidade.

Este artigo propõe apresentar a audiodescrição como recurso de tecnologia assistiva voltado para deficientes visuais. Ele visa contribuir para a divulgação da AD, ainda pouquíssimo conhecida em nosso país, aí incluídas as suas esferas de produção acadêmica e cultural como um todo. Por isso, o presente trabalho dirige-se principalmente àqueles que tenham interesse em conhecer os fundamentos desse recurso tão relevante para a sociedade. Como indica o título em sua ambiguidade deliberada, pretende-se aqui propiciar os primeiros passos desses leitores ao encontro do mundo da $\mathrm{AD}$, apresentando-lhes, por outro lado, os primeiros passos da $\mathrm{AD}$ no mundo e, principalmente, no cenário brasileiro.

Com esse propósito, será feita uma breve história do surgimento e desenvolvimento da $\mathrm{AD}$ como conhecimento técnico-científico e como prática institucionalizada, tendo-se a preocupação de detalhar as principais características desse 
recurso, suas diferentes formas de realização, em contextos diversos, e os principais profissionais e funções que ele compreende.

\section{Uma história da AD como conhecimento técnico-científico e como prática institucionalizada}

A audiodescrição é a transformação de imagem em texto, transformação essa que primeiramente se dá como escrita de um texto denominado "roteiro", o qual, posteriormente, passará pelo processo conhecido como "narração", isto é, a leitura do roteiro para o público-alvo. A AD é realizada em produtos audiovisuais como peças teatrais, cinema e televisão, e em produtos só visuais, como por exemplo quadros e esculturas expostos em museus. O principal objetivo da AD é tornar esses eventos culturais acessíveis aos deficientes visuais - conceito que abrange pessoas cegas e com baixa visão, congênita ou adquirida. Também se beneficiam desse recurso pessoas com deficiência intelectual e dislexia, como explica Livia Motta:

A audiodescrição amplia, assim, o entendimento não somente das pessoas com deficiência visual, como também de pessoas com deficiência intelectual, pessoas com dislexia e pessoas idosas. Ou seja, uma plena participação dos diferentes públicos: que todos possam apreciar as artes e a cultura, com a eliminação de barreiras físicas, atitudinais e comunicacionais (2010: 58).

A audiodescrição como conhecimento técnico-cientifico e prática institucionalizada começou nos Estados Unidos, na década de 1970, com o estudo de Gregory Frazier para sua dissertação de mestrado. Na década de 1980, as iniciativas no campo da audiodescrição se proliferaram e, ao final dela, mais de cinquenta estabelecimentos nos Estados Unidos produziam espetáculos audiodescritos. Foi nesse final dos anos oitenta que a $\mathrm{AD}$ começou a ser difundida na Europa, e as pesquisas acadêmicas sobre a técnica foram iniciadas na década de 1990. A maior parte do que se produz na academia sobre o assunto vem se dando na área dos Estudos da Tradução a partir de 2000, embora a audiodescrição também seja abordada no âmbito dos Estudos de Tecnologia Assistiva e de Educação Especial. Atualmente, os países que mais investem na $\mathrm{AD}$ são Estados Unidos, Alemanha, Espanha, França, Bélgica, Canadá, Austrália e Argentina (ver Franco, 2007; Franco \& Silva, 2010: 19-36).

Se a AD já é uma realidade nos Estados Unidos e na Europa, aqui no Brasil ela ainda dá seus primeiros passos. Foi somente em 2003, portanto mais de vinte anos após a sua adoção naquelas regiões, que ocorreu o primeiro evento com audiodescrição em nosso país, o qual foi feito ao vivo. Trata-se do festival de filmes sobre deficiências 
chamado Assim Vivemos, o qual ocorre bienalmente no Centro Cultural Banco do Brasil de diferentes cidades, como Rio de Janeiro e São Paulo.

Outras iniciativas pioneiras, em diferentes áreas, foram as seguintes:

- em 2005, o lançamento do filme "Irmãos de fé” em DVD, com AD e menu acessível;

- em 2006, a peça “O santo e a porca”, exibida em São Paulo com AD;

- em 2007, a primeira mostra de filmes com audiodescrição pré-produzida, no projeto Cinema Nacional Legendado e Audiodescrito, evento também realizado no Centro Cultural Banco do Brasil; e,

- em 2008, a propaganda da Natura e o espetáculo de dança “Os três audíveis", os primeiros a contar com o recurso nessas áreas.

Cabe aqui uma explicação técnica acerca das duas modalidades de audiodescrição que foram mencionadas acima, em referência aos dois eventos cinematográficos realizados no CCBB: a "audiodescrição ao vivo", na qual o roteiro é escrito antecipadamente, mas a narração é realizada no momento da exibição do filme, através da utilização de equipamentos de tradução simultânea; e a "audiodescrição préproduzida", a qual, distintamente da anterior, tem a narração (e não só o roteiro) preparada previamente à exibição do produto audiovisual, ao qual ela é mixada depois de gravada e editada. Nos dois casos, ao vivo e pré-produzida, as ADs chegam aos deficientes visuais através de fones de ouvido.

Apesar de ainda dar os primeiros passos, a AD vem se consolidando e se tornando uma realidade cada vez mais presente entre nós. Flavia Machado criou o blog Com audiodescrição para mapear as iniciativas que vêm se dando nesse campo em nosso país. Lá é possível constatar um aumento importante no número de filmes exibidos e de DVDs lançados com esse recurso, seja em projetos com distribuição restrita a instituições voltadas para pessoas com deficiência visual, seja em projetos comerciais. Desde 2008, há, por ano, pelo menos um espetáculo de dança audiodescrito e, desde 2009, alguns espetáculos de ópera contam com esse recurso. O aumento das produções de teatro com AD também é digno de nota: em 2006, um espetáculo contou com audiodescrição; em 2007 e 2008, seis espetáculos utilizaram esse recurso; e, a partir de 2009, o número gira em torno de vinte. Em São Paulo, quatro locais oferecem permanentemente o serviço de AD - Teatro Vivo, Espaço Perfume Arte + História, Museu do Ipiranga e Memorial da Inclusão. 
Acrescente-se o fato de que, no dia $1^{\text {o }}$ de julho de 2011, começou a obrigatoriedade do uso desse recurso de tecnologia assistiva em duas horas semanais da programação da TV digital aberta e, três meses após o início da obrigatoriedade, ainda segundo o blog de Machado, 24 filmes com AD foram transmitidos pela TV Globo, 12 edições do programa Chaves foram transmitidos pelo SBT, e 12 edições do programa Comédia MTV foram exibidos na TV de mesmo nome. A TV Brasil e a TV Record anunciaram os programas que exibiriam com audiodescrição logo no início da obrigatoriedade, mas não foram encontradas informações que confirmassem a realização de tais transmissões. A TV Bandeirantes, pelo que se sabe, não se manifestou até o momento. $\mathrm{O}$ que se conclui é que, se essas emissoras estão de fato cumprindo a legislação, elas não estão fazendo uma divulgação adequada, o que, de qualquer modo, foge aos propósitos da acessibilidade e inclusão social.

A ONCB - Organização Nacional de Cegos do Brasil — realizou uma pesquisa nos dois meses iniciais da obrigatoriedade (julho e agosto de 2011) para traçar um panorama da recepção da audiodescrição. O resultado da pesquisa não foi divulgado até o momento da presente publicação, mas cabe aqui registrar que o que motivou tal pesquisa foi a dificuldade de acesso ao sinal, conforme relatado no ofício da ONCB, disponível no site da instituição:

As dificuldades de acesso ao recurso têm ocasionado grande decepção para essas pessoas, que aguardavam há tanto tempo a oportunidade de assistirem à programação televisiva em igualdade de condições com as demais pessoas, mesmo que por apenas duas horas na semana.

Além de ser necessário um aparelho com sinal digital ou, na falta deste, um conversor, os controles remotos de um modo geral no Brasil (diferentemente de outros países, como o Reino Unido) não estão adaptados, isto é, não possuem qualquer indicação sensorial. Além disso, cada tipo ou marca de televisor tem acesso e layout diferente em seus menus, o que tira a autonomia daquele que necessita desse serviço, implicando na necessidade de que uma pessoa vidente lhe preste auxílio entrando no menu e acionando o canal de áudio 3, destinado à audiodescrição.

O descaso com a implementação da audiodescrição é antigo. A Lei Federal 10.098, de dezembro de 2000 (ver nas referências "Brasil [...] 2000"), após sua regulamentação e consulta pública, tornou a audiodescrição um direito garantido. Essa lei - que foi regulamentada pelo Decreto 5.296, o qual foi alterado pelo Decreto 5.645, que por sua vez foi alterado pelo Decreto 5.762 (ver "Brasil [...] 2004/2005/2006") — 
obrigaria as emissoras de televisão a oferecerem duas horas diárias de sua programação com audiodescrição. Essa quantidade de horas aumentaria gradativamente, até que, ao final de dez anos, toda a programação estivesse disponível com esse recurso. Em 2008, venceu o prazo para o início do uso da audiodescrição na televisão; foram então publicadas duas portarias, a primeira postergando e a segunda suspendendo o início da implementação da lei. Em março de 2010, uma nova portaria entrou em vigor determinando que a partir de $1^{\circ}$ de julho as emissoras que já transmitissem em canal digital aberto teriam 12 meses para começar a fazer a audiodescrição, em duas horas semanais e não mais diárias (Brasil [...] 2010). O número de horas provavelmente vai aumentar de modo gradativo, mas em dez anos deverá atingir o máximo de vinte horas semanais da programação e não mais a sua totalidade.

Na esfera acadêmica a AD vem se tornando cada vez mais visível e, assim como na Europa, é reconhecida como uma modalidade de tradução audiovisual intersemiótica com vistas à acessibilidade. No Brasil, hoje, temos três importantes pesquisadores na área e, em decorrência disso, três importantes polos de pesquisa: um na UFBA, coordenado pela professora Eliana Franco; outro, na UECE, coordenado pela professora Vera Lucia Santiago Araújo; e o terceiro, na UFPE, coordenado pelo professor Francisco Lima.

O começo da obrigatoriedade da transmissão da AD na TV é fruto de mais de dois anos de briga entre as emissoras, o governo, especificamente o Ministério das Comunicações, e grupos sociais envolvidos na busca pela garantia da implementação de medidas de acessibilidade. Nesse período houve grande aumento na divulgação da AD como recurso de tecnologia assistiva e como uma modalidade de tradução. Ainda se faz muito necessário ampliar a divulgação da $\mathrm{AD}$ para que mais pessoas a conheçam e possam dela se beneficiar. Também se faz necessário divulgar a ideia de que esse recurso constitui um tipo de tradução, já que boa parte da parcela do público e das emissoras que conhecem a audiodescrição não a identificam como uma atividade tradutória.

O avanço na consolidação da AD no Brasil, apesar de significativo, ainda está longe de ser suficiente. A oferta da audiodescrição não deve ser vista como um favor ou como uma obrigação ou imposição legal. O desejo daqueles, ainda poucos, que vêm travando a longa e dura batalha para conquistar a adoção universal da audiodescrição é o de que ela se transforme em prática democrática rotineira, graças a uma sociedade 
mais e mais inclusiva - a AD precisa ser entendida como um recurso que possibilita a participação de todos no processo de socialização.

\section{AD: de que formas pode ser feita e quem a faz}

Nesta seção serão apresentados em detalhe os principais aspectos terminológicoconceituais da $\mathrm{AD}$, alguns dos quais já foram mencionados, acima, de modo breve. Trata-se, sobretudo, de aspectos associados às técnicas de audiodescrição e seus realizadores.

Ana Isabel Hernández Bartolomé e Gustavo Mendiluce Cabrera, no artigo "La semiótica de la traducción audiovisual para invidentes" (2005: 246), afirmam que a AD é um processo complexo do qual participam diversos profissionais, dentre os quais se destacam o audiodescritor e o locutor. Estes são responsáveis pelas duas etapas primordiais da audiodescrição, respectivamente, a elaboração do roteiro e a sua locução ou narração, feita, esta, em um canal de som complementar ao do produto audiovisual. O texto produzido pelo audiodescritor é designado "roteiro", por funcionar como um guia que orienta uma equipe de produção para a gravação e edição do áudio (2005, p. 246).

A audiodescrição pode ser gravada, ao vivo, ou simultânea:

- em filmes e programas de TV que são pré-produzidos, ou seja, que não são ao vivo, o roteiro e a locução são preparados antes da exibição;

- em peças teatrais, visitas a museus, programas de TV ao vivo, nos quais há margem para inovações "fora do script", o roteiro é elaborado antecipadamente, mas a locução da AD é feita no momento do evento; $\mathrm{e}$

- em programas, paradas ou reportagens de última hora e sem ensaio, fica inviabilizada a preparação do roteiro, daí decorrendo que a audiodescrição é integralmente feita no momento do evento.

Veja-se que na $\mathrm{AD}$ ao vivo e na $\mathrm{AD}$ simultânea, o audiodescritor necessariamente tem que ser o locutor, pois, na primeira, a obra pode sofrer alterações ao ser exibida e, por isso, exigir que sejam feitas adaptações no roteiro, enquanto que na simultânea o roteiro é elaborado no momento do evento. Já na AD gravada, o audiodescritor e o locutor podem ser profissionais diferentes, uma vez que o produto audiovisual não sofrerá mudanças e, em decorrência disso, tampouco o roteiro. 
Jorge Díaz Cintas, no artigo "Por una preparación de calidad en accesibilidad audiovisual", estabelece três grandes categorias para a identificação de diferentes tipos e formas de produção da $\mathrm{AD}$ :

a) $\mathrm{AD}$ gravada para a tela: de programas audiovisuais com imagens dinâmicas, como filmes, séries de televisão, documentários, espetáculos, etc., independente do meio em que será distribuído ou comercializado (televisão, cinema, DVD, internet);

b) AD gravada para audioguia: de obras estáticas como monumentos, museus, galerias de arte, igrejas, palácios, exposições, entornos naturais e espaços temáticos em que não haja imagens dinâmicas e em que a experiência tátil, ou novas tecnologias que simulem esse tipo de experiência, têm uma grande importância; e

c) $\mathrm{AD}$ ao vivo: de obras teatrais, musicais, balé, ópera, esportes e outros espetáculos similares. Também entram nessa categoria congresso e qualquer manifestação pública como os atos políticos. (2007: 50, tradução nossa)

Essa categorização de Díaz Cintas difere daquela apresentada mais acima, na medida em que ele subdivide a audiodescrição em função de apenas duas formas: gravada e ao vivo; e distingue os produtos passíveis de audiodescrição em torno de três tipos: “imagens dinâmicas", "obras estáticas" e "espetáculos ou manifestações públicas" — a esse terceiro tipo de evento, ele associa a "AD ao vivo", e aos dois primeiros, a "AD gravada".

Ou seja: se a classificação apresentada anteriormente à de Díaz Cintas tem como um critério básico a anterioridade ou a simultaneidade da locução e da escrita do roteiro relativamente à exibição do produto ou realização do evento, a classificação do autor espanhol parece privilegiar a natureza do objeto audiodescrito. Fundindo-se as duas formas de recortar o campo da $\mathrm{AD}$, pode-se chegar à seguinte síntese: imagens estáticas e dinâmicas, dependendo do caso, podem ser audiodescritas por meio de gravação (com preparação do roteiro e locução gravada antes do evento), ao vivo (com preparação antecipada do roteiro e locução no momento do evento), ou de forma simultânea (com a preparação do roteiro e a locução no exato momento do evento).

Cabe agora examinar em certo grau de minúcia as etapas necessárias à produção de cada tipo de audiodescrição, num total de cinco (ou seis), dependendo de a AD ser gravada, ao vivo ou simultânea, e de as imagens, por sua vez, serem dinâmicas ou estáticas. Começa-se por aquela que compreende o maior número de etapas, a $A D$ gravada de imagens dinâmicas, a qual, após a determinação do material audiovisual a ser audiodescrito, vai se constituindo através do seguinte processo:

1) assistir ao produto audiovisual, analisando a importância (relevância) das imagens para a narrativa. Marcar as cenas mais importantes, bem como aquelas 
em que o tempo para a descrição é escasso, para que mais tarde, durante a elaboração do roteiro, o audiodescritor possa fazer escolhas compatíveis com o contexto do programa e com os intervalos de silêncio.

2) Elaborar o roteiro. Uma das características mais básicas da audiodescrição é a de que ela é inserida nos silêncios do produto audiovisual, entre as falas de personagens, por exemplo. Na elaboração do roteiro, além da escolha das palavras que melhor descrevem as imagens, o audiodescritor deve marcar o tempo de entrada de cada inserção de descrição. $O$ roteiro precisa ser cronometrado de modo a caber nos tempos de silêncio. Nesta etapa, o audiodescritor deve se preocupar principalmente com dois aspectos, sendo o primeiro deles a sincronia do produto - o ideal seria a sincronia total entre imagem e narração, mas como na prática isso é pouco realizável, torna-se necessário, na maior parte das vezes, antecipar as descrições relativamente às imagens; o segundo aspecto desta etapa de elaboração do roteiro que exige atenção por parte do audiodescritor é a não repetição de um elemento que já esteja presente no áudio, de modo a evitar uma informação duplicada e a não desperdiçar espaço, o qual, como já se viu, é com frequência escasso. O êxito das descrições das imagens depende de sua eficiente integração no conjunto do áudio do produto.

3) Testar o roteiro oralmente (ensaiar para a gravação). Uma vez que o roteiro esteja pronto no que concerne à sua escrita, passa-se para a sua leitura em voz alta, a qual permite que se façam variados ajustes no texto. Além de se reelaborar o vocabulário e o estilo do texto, comumente feitos nas revisões textuais, o ajuste mais importante a se fazer, no caso específico do roteiro para a audiodescrição, consiste em adequar cada descrição ao respectivo tempo de silêncio.

4) Gravar o roteiro. Quando o audiodescritor grava o roteiro que escreveu, os volumes do áudio do filme precisam ser ajustados ao volume da narração da audiodescrição.

5) Revisar a gravação para corrigir os erros e omissões, evitando possíveis imperfeições na $\mathrm{AD}$ e verificando se os critérios intersemióticos foram preservados para não alterar o valor estético da obra audiovisual (ver Hernandes Bartolomé \& Mendiluce Cabrera, 2005: 246). 
Como é possível perceber por suas etapas acima descritas, a audiodescrição gravada de imagens dinâmicas constitui-se como um texto multimodal, posto que o roteiro - além de necessariamente envolver escrita e oralidade (a narração ou locução é a única razão de ser de um roteiro de $\mathrm{AD}$ ) — só ganha sentido em conjunto com a obra original, a qual, por sua vez, contém elementos verbais (falas dos personagens e eventuais informações escritas, cartazes, por exemplo) e elementos auditivos não-verbais (ambiência sonora de modo geral, sons da natureza, por exemplo).

$\mathrm{Na} A D$ ao vivo de imagens dinâmicas, como em uma peça de teatro ou um programa de TV ao vivo, o audiodescritor vai até a terceira etapa, momento em que revisa o material, isto é, testa o roteiro oralmente. A etapa seguinte, que é a última, consiste na locução, a qual é feita no momento do evento e, como já indicado anteriormente, com a possibilidade de ajustes (menos ou mais significativos) do roteiro, devido a modificações no produto durante a apresentação.

Já na $A D$ simultânea de imagens dinâmicas, o audiodescritor se atém somente ao item dois, embora com diferenças importantes. Antes de mais nada, cabe chamar atenção para o fato, interessante, de que na $\mathrm{AD}$ simultânea há toda uma gradação de simultaneidade, digamos assim - ela pode ser totalmente improvisada, num extremo dessa gradação, ou pode contar com algum tipo de preparação, como por exemplo no contexto de um congresso, se o audiodescritor tem a chance de ter algum contato prévio com o palestrante cujo trabalho será audiodescrito. Nesse caso não há roteiro, ou, em outros termos, pode-se dizer que roteiro e locução são uma só e mesma coisa. Sem conhecer o produto, o audiodescritor terá dificuldade em escolher tanto os melhores momentos para inserir a descrição quanto os elementos a serem priorizados. Ou seja, a sincronia e a escolha das palavras ficarão prejudicadas e, por isso, a AD simultânea deve ser escolhida somente como último recurso.

No caso da $A D$ de imagens estáticas (ver a categoria b de Díaz Cintas, acima), as etapas necessárias à sua produção assemelham-se com as etapas da AD gravada de imagens dinâmicas. Primeiro, é necessário ter contato com a imagem, observando seus detalhes. Em uma segunda etapa, elabora-se o roteiro, indo do geral para o específico em uma sequência lógica que segue de cima para baixo, da esquerda para a direita, do primeiro plano para o plano intermediário e o de fundo - e usando vocabulário amplo que consiga abarcar as diferentes características do objeto, tais como forma, tamanho, cor, textura, disposição espacial e técnica artística. Apesar de a AD de imagens estáticas não sofrer restrições de tempo tão prementes como no caso das imagens dinâmicas, as 
descrições não devem ser longas, pois se tornam cansativas. Após o contato com a imagem e a elaboração do roteiro, as etapas são a gravação e a revisão das descrições, no caso de a locução ser gravada. Se a locução for ao vivo, o audiodescritor deve revisar o material e o locutor, na última etapa, narrará as descrições (ver Lima, 2011: s.p.). Quanto às descrições simultâneas dessas imagens estáticas, elas coincidem com as ADs simultâneas de imagens dinâmicas na medida em que não há roteiro.

Olhando-se para a audiodescrição sob a perspectiva que privilegia a oposição imagem dinâmica / imagem estática, pode-se dizer que no caso da $\mathrm{AD}$ de imagens dinâmicas, o audiodescritor deve contemplar as questões “o quê?”, “quem?”, “como?”, “quando?" e “onde?" (ver Vercauteren, 2007a: 142); e, no caso da AD de imagens estáticas, o audiodescritor deverá se ater à pergunta “como é o objeto?" (ver Lima, 2011: s.p.).

Além desses "deveres" norteados pelas questões espaço-temporais, várias recomendações circulam entre os audiodescritores, como, por exemplo, as que preconizam que não se deve sintetizar e não se deve dar informações importantes cedo demais para não contar uma piada antes da hora ou, digamos, acabar com o suspense num filme (ver Franco, 2006). Tais orientações não são universais, ou seja, variam entre regiões ou países, como por exemplo entre a Espanha e o Reino Unido. Aqui no Brasil, a ABNT conta, no presente momento, com grupos de trabalho para elaboração de uma nova normatização para AD. Porém, há um pilar central, unânime, na audiodescrição: "descreva o que você vê".

Um exemplo de como regras e orientações são colocadas em prática por audiodescritores é o estudo "Una gramática local del guión audiodescrito. Desde la semántica de un nuevo tipo de traducción" (2007), de Catalina Jimenez Hurtado, uma das pesquisadoras mais importantes do campo da AD. Nesse seu trabalho, que se tornou referência para muitos audiodescritores - constituindo-se como teoria que parte da prática e que volta a ela - , a autora apresenta as bases epistemológicas e linguísticas de uma gramática local do texto audiodescrito, a partir da análise de um corpus de mais de duzentos roteiros de filmes audiodescritos. Hurtado mostra que "o tradutor/audiodescritor reescreve todo o conjunto de imagens em um texto, atendo-se a uma série de regras gramaticais e discursivas. Estamos diante da criação de uma série de estruturas linguísticas recorrentes que nos permitirão criar uma gramática local do mesmo [roteiro]" (Hurtado, 2007: 64, tradução e grifo nossos). Entre essas regras estão, por exemplo, o tipo de oração que se utiliza para descrever emoções, sentimentos, ou os 
sintagmas mais recorrentes para descrever a localização de algo em determinado lugar ou tempo (ver Hurtado, 2006: 149). A autora informa que foi utilizado um software de análise textual para "etiquetagem" dos elementos semânticos presentes nos roteiros de AD. Essas etiquetas foram organizadas hierarquicamente, das categorias mais gerais para as mais especificas, e foram sendo compostas a partir da seleção dos lexemas mais utilizados. Os parâmetros mais gerais por ela identificados nas audiodescrições foram três: elementos visuais não verbais; elementos visuais verbais; e estilo. Vejam-se brevemente cada um deles:

- o primeiro subdivide-se em i) personagens - por exemplo, "identificação do ator/atriz que interpreta o personagem" e "atributos físicos" desse último, como 'etnia' e 'linguagem corporal', além de "estados", como os 'emocionais' ou 'mentais'; ii) ambientação - como "localização espacial" e "descrição de ambientes internos e externos; e iii) ações;

- o segundo refere-se aos créditos e às inserções, sendo as "legendas" um exemplo dessas últimas;

- o terceiro diz respeito, por exemplo, a um "estilo com tom literário", o uso (ou não) de "metalinguagem cinematográfica" e um "estilo adaptado ao dialeto utilizado no filme". (Hurtado, 2007: 69-70).

Em toda essa análise de Hurtado, pode-se perceber sua preocupação com a forma das audiodescrições, como também - e sobretudo - com o conteúdo do produto audiovisual que deve ou não ser descrito, para usar uma dicotomia já bastante discutida. É a partir dessa verificação das "estruturas linguísticas” mais utilizadas nos roteiros, que a autora mostra, por exemplo, que são mais importantes e estatisticamente mais frequentes as informações que se relacionam com a mudança de ação num filme e com o objeto que atrai a atenção dos personagens. Uma outra conclusão a que ela chega é a de que o audiodescritor, ao traduzir o conteúdo visual, deve levar em conta o conteúdo acústico para não traduzir elementos visuais facilmente deduzíveis pelo conteúdo auditivo.

Vê-se aí um aspecto fundamental na audiodescrição: “o que descrever”. Buscar não só um volume de informações suficiente para o público acompanhar a história, sem que a $\mathrm{AD}$ se torne cansativa, como também a melhor maneira de dar essas informações. Trata-se de uma tarefa, no entanto, que não é nada simples se levarmos em conta que, ao lado da regra de ouro da $\mathrm{AD}$, “descreva o que você vê", já aqui citada, considera-se necessário adotar a seguinte orientação: "não interpretar". 
É possível descrever o que se vê sem interpretar? Vera Lúcia Santiago Araújo assinala, tendo como base o artigo de Hurtado, que essa autora quebra o mito de que o audiodescritor não deve interpretar, pois a estrutura frasal mais encontrada nas audiodescrições, em 30\% dos casos, foi sujeito-predicado-predicativo, e o predicativo nesse tipo de construção implica justamente a ocorrência de interpretação (Ver Hurtado, 2007: 77, Santiago, 2010: 86-7). Vejam-se as ponderações de Araújo:

Devemos saber que, ao fazermos uma narrativa, sempre deixamos nossas impressões e nossa visão de mundo. $\mathrm{O}$ audiodescritor só precisa tomar cuidado na escolha de sua adjetivação para não colocar suas inferências no texto, principalmente aquelas cruciais para o entendimento do filme. A garantia da acessibilidade reside em que a leitura do filme seja feita pelo espectador, seja ele vidente, ouvinte, surdo ou com deficiência visual. Não faz parte do trabalho do audiodescritor facilitar essa leitura. Ele precisa traduzir as imagens para propiciar à pessoa com deficiência visual a oportunidade de fazer a própria interpretação (2010, p. 86-7).

Vercauteren (2007b), assim como Santiago, defende que a interpretação está presente no trabalho do audiodescritor. Contudo, ele afirma que, à medida que passarem a contar com a elaboração de recomendações ou orientações consistentes, os novos audiodescritores saberão lidar melhor com ela, diminuindo-a. De acordo com o autor, "a natureza implícita dos filmes significa, pois, que descrever imagens sempre implica em interpretar o que se vê. Se queremos fornecer descrições mais embasadas, teremos que oferecer aos novos audiodescritores recomendações que os ajudem a restringir a interpretação" (2007b: s.p., tradução nossa). Esse ponto discutido por Araújo e Vercauteren ainda precisa ser melhor investigado. O que significa "reduzir ao mínimo a interpretação"? Quais são as diferenças entre descrever e interpretar na AD? ${ }^{1}$

\section{Considerações Finais}

Procurou-se neste artigo traçar um panorama da audiodescrição. Um panorama que abrangesse um pouco da sua história, em outros países e especialmente no Brasil, e que apresentasse suas diferentes modalidades, em função dos diferentes tipos de evento ou de produto em que é usada. Também procurou-se enfatizar a extrema relevância social da AD, e daí a necessidade de divulgá-la e fortalecê-la entre nós. Por se tratar de uma profissão ainda não regulamentada, que só recentemente vem sendo ensinada, de um modo geral em cursos livres, sem um currículo fixo, é urgente discutirem-se as suas

1 Essa temática constitui o eixo norteador da tese de doutorado em elaboração por Larissa Costa, principal autora do presente trabalho. 
regras. Visto que a quantidade de produtos audiodescritos e o número de profissionais atuantes vêm aumentando, tornam-se prementes estudos nesse campo que auxiliem na formulação de recomendações em nosso país, visto que as que hoje utilizamos, em sua grande maioria, são importadas de modelos estrangeiros, sobretudo da Espanha, Reino Unido e Estados Unidos. Tais formulações deverão ser abrangentes o bastante para se adequarem a diferentes segmentos do público brasileiro, que em geral, por razões socioeconômicas, não vai com frequência aos cinemas, teatros e museus.

\section{Referências:}

ARAÚJO, Vera Lucia Santiago. A formação de audiodescritores no Ceará e em Minas Gerais: uma proposta baseada em pesquisa acadêmica In: Audiodescrição: transformando imagens em palavras. São Paulo: Secretaria dos Direitos da Pessoa com Deficiência do Estado de São Paulo, 2010.

BRASIL. Decreto n ${ }^{\circ} 5.296$, de 2 de dezembro de 2004.

BRASIL. Decreto $\mathrm{n}^{\circ} 5.645$, de 28 de dezembro de 2005.

BRASIL. Decreto n ${ }^{\circ} 5.762$, de 27 de abril de 2006.

BRASIL. Lei $\mathrm{n}^{\mathrm{o}}$ 10.098, de 19 de dezembro de 2000. Disponível em: http://www.planalto.gov.br/ccivil_03/Leis/L10098.htm

BRASIL. Ministério das Comunicações. Portaria nº 188 de 24/03/2010. Disponível em: http://www.mc.gov.br/images/documentacaoacessibilidade/acessibilidade_188.pdf. Acesso em: 05 jan 2011.

DÍAZ CINTAS, Jorge. Por una preparación de calidad en accesibilidad audiovisual. Trans. Revista de Traductología 11, 2007. p. 45-59.

FRANCO, Eliana P. C.. Legenda e áudio-descrição na televisão garantem acessibilidade a deficientes. Revista Ciência e Cultura, São Paulo, v.58, n.1, p.12-13, mar 2006. Disponível em: http://cienciaecultura.bvs.br/scielo.php?script=sci_arttext\&pid=S0009$\underline{67252006000100008 \& \operatorname{lng}=p t \& n r m=i s o}$ Acesso em: 10 jun 2011.

FRANCO, Eliana. Audiodescrição e Audiodescritores: Quem é Quem?, 2007. Disponível em: http://elianafranco.wordpress.com/ Acesso em: 15 mai 2011.

FRANCO, Eliana \& SILVA, Manoela Cristina Correia Carvalho. Audiodescrição: breve passeio histórico In: Audiodescrição : transformando imagens em palavras. São Paulo: Secretaria dos Direitos da Pessoa com Deficiência do Estado de São Paulo, 2010.

HERNANDEZ BARTOLOMÉ, Ana I. \& MENDILUCE CABRERA, Gustavo. La semiotica de la traducción audiovisual para invidentes. Revista de la Asociación 
Española de Semiotica, $\mathrm{n}^{\mathrm{o}} 14$, 2005. Disponível em: http://descargas.cervantesvirtual.com/servlet/SirveObras/00362842088072840032 268/029215.pdf?incr=1 Acesso em: 20 nov 2011.

HURTADO, Catalina J. De imágenes a palabras: La audiodescripción como uma nueva modalidad de traducción y de representación Del conocimiento. In: WOTJAK, G. (Ed.) Quo vadis translatogie? Ein halbes Jahrhundert universitare Ausbildung von Dolmetschern und Übersetzern in Leipzig. Frank\&Time, $2006 . \quad$ Disponível em: http://books.google.com/books?hl=en\&lr=\&id=NUNtOs9yDIAC\&oi=fnd\&pg=P A143\&dq=audiodescripci\%C3\%B3n\&ots=aw_6D4eOYB\&sig=pOyggVY6rCPO sjaiEFStRcflyEM\#v=onepage \&q=audiodescripci\%C3\%B3n\&f=false Acesso em: 20 jul 2011.

HURTADO, Catalina J. Una gramática del guión audiodescrito. Desde la semántica a la pragmática de un nuevo tipo de traducción In: (Ed.) Traducción y accesibilidad: subtitulación para sordos $y$ audiodescripción para ciegos: nuevas modalidades de Traducción Audiovisual. Frankfurt: Peter Lang, 2007.

LIMA, Francisco. Áudio-descrição: arte e linguagem a serviço da pessoa com deficiência visual. Disponível em: http://www.lerparaver.com/node/10690 Acesso em: 05 out 2011

MACHADO, Flavia. Blog Com audiodescrição: http://comaudiodescricao.blogspot.com/. Acesso em 05 out 2011.

MAZZONI, Alberto Angel et al . Aspects that interfere in structuring the accessibility at public libraries. Ci. Inf., Brasília, v. 30, n. 2, 2001. Disponível em: http://www.scielo.br/scielo.php?script=sci_arttext\&pid=S010019652001000200005\&lng=es\&nrm=iso Acesso em: 09 mai 2011.

MORAES, Denis (Org). Sociedade midiatização. Rio de Janeiro: Mauad, 2006.

MOTTA, Livia. A audiodescrição vai à ópera In: Audiodescrição: transformando imagens em palavras. São Paulo: Secretaria dos Direitos da Pessoa com Deficiência do Estado de São Paulo, 2010.

Site

do

IBGE:

http://www.ibge.gov.br/home/presidencia/znoticias/noticia_visualiza.php?id_noticia=17 $\underline{08}$. Acesso em $27 \mathrm{dez} 2011$.

Site ONCB: $\quad$ http://www.oncb.org.br/pesquisa-nacional-de-recepcao-daaudiodescricao.html. Acesso em 05 out 2011

VERCAUTEREN, Gert. Towards a European guideline for audio description In: DÍAZ CINTAS, Jorge (Org.). Media for all: Subtitling for the Deaf, Audiodescription, and Sign Language. New York: Rodopi, 2007a.

VERCAUTEREN, Gert. Can relevance-oriented insights in film editing techniques help audio describers prioritise information?. In:MUTRA: audiovisual translation scenarios, 2007, Copenhagen. Abstracts. Copenhagen:University of Copenhagen, $2007 \mathrm{~b}$. 